\title{
Results of 2003 Early, Mid and Full Season, and Roundup Ready Cotton Variety Tests in Florida ${ }^{1}$
}

\section{D.L. Wright, P.J. Wiatrak, J.J. Marois and B. Kidd ${ }^{2}$}

Cotton was planted with a cone planter at the seeding rate of 85 seeds/ $20 \mathrm{ft}$ of row with 36 " row spacing on 5 May, 2003 after strip tilling into tilled small grain cover crops. Thimet $20 \mathrm{G}$ was applied in furrow at $6.5 \mathrm{lb} / \mathrm{A}$.

\section{Early Season Cotton Variety Trial}

Sixteen cotton varieties were planted in this trial on 12 May. On 13 May, the study was fertilized with 3-9-18 ( $\left.\mathrm{N}-\mathrm{P}_{2} \mathrm{O}_{5}-\mathrm{K}_{2} \mathrm{O}\right)$ fertilizer at $400 \mathrm{lb} /$ A placed 2-3 inch from the planted row using an FP row fertilizer applicator. The variety trial was broadcast sprayed with Cotoran @1 qt/A + Prowl @ 1 qt/A on 15 May, Cotoran@1 pt/A+Bueno 6 @ 1 pt/A on 2 June, and Dual II Magnum @ 1 pt/A on 6 June. On 10 June, cotton was side-dressed with ammonium nitrate $(34 \% \mathrm{~N})$ at $176.5 \mathrm{lb} / \mathrm{A}(60 \mathrm{lb} \mathrm{N} / \mathrm{A})$. The study was direct sprayed with Cotoran @ 1 qt/A + Karmex @ 1.5 lb/A + Induce @ 2 qt/100 gal of solution on 23 June and broadcast sprayed with Mepex @12 oz/A + Agridex oil @ 2 pt/A + Kinetic @ 9 oz/100 gal of solution on 30 June, Poast Plus @ 3.75 pt/A +
Agridex oil @ 2 pt/A on 9 July, Mepex @ 12 oz/A + Agridex oil @2 pt/A + Kinetic@ @ oz/100 gal of solution on 17 July, Mepex @ 16 oz/A + Agridex oil @ 2 pt/A + Kinetic@ 9 oz/100 gal of solution on 30 July, Penncap M @ 3 pt/A on 31 July, Mepex @ 8 oz/A + Induce@1 qt/A on 14 August, Baythroid 2 @ 2.6 oz/A + Induce @ 1 qt/A on 25 August, and defoliated with Finish@1.5 pt/A + Ginstar@6 oz/A on 2 October. On 1 November, the early variety trial was picked with the International Cotton Spindle Picker. The plot area was irrigated with 0.25 inch water on 9 May and 0.5 inch water on 13 May.

\section{Mid and Full Season Cotton Variety Trial}

The mid and full season variety trial was planted with sixteen cotton varieties on 14 May. The same day, cotton was fertilized with 3-9-18 ( $\left.-\mathrm{P}_{2} \mathrm{O}_{5}-\mathrm{K}_{2} \mathrm{O}\right)$ fertilizer at $400 \mathrm{lb} /$ A placed 2-3 inch from the planted row using an FP row fertilizer applicator. The study was broadcast sprayed with Cotoran @ $1 \mathrm{qt} / \mathrm{A}+$ Prowl @1 qt/A on 15 May, Cotoran@1 pt/A +

1. This document is SS-AGR-222, a publication of the Agronomy Department, Florida Cooperative Extension Services, Institute of Food and Agricultural Sciences, Univeristy of Florida. Publication date April 2004. Please visit the EDIS web site at http://edis.ifas.ufl.edu.

2. D.L. Wright, professor, Agronomy Department, North Florida Research and Education Center-Quincy, FL; P.J. Wiatrak, assistant in Agronomy, North Florida Research and Education Center-Quincy, FL; J.J. Marois, professor, Plant Pathology Department, North Florida Research and Education Center-Quincy, FL; B. Kidd, biological scientist, North Florida Research and Education Center-Quincy, FL; Florida Cooperative Extension Service, Institute of Food and Agricultural Sciences, University of Florida, Gainesville, FL 32611.

The use of trade names in this publication is solely for the purpose of providing specific information. UF/IFAS does not guarantee or warranty the products named, and references to them in this publication does not signify our approval to the exclusion of other products of suitable composition.

The Institute of Food and Agricultural Sciences (IFAS) is an Equal Opportunity Institution authorized to provide research, educational information and other services only to individuals and institutions that function with non-discrimination with respect to race, creed, color, religion, age, disability, sex, sexual orientation, marital status, national origin, political opinions or affiliations. U.S. Department of Agriculture, Cooperative Extension Service, University of Florida, IFAS, Florida A. \& M. University Cooperative Extension Program, and Boards of County Commissioners Cooperating. Larry Arrington, Dean 
Bueno $6 @ 1$ pt/A on 2 June, and Dual II Magnum @ $1 \mathrm{pt} / \mathrm{A}$ on 6 June. On 10 June, cotton was side-dressed with ammonium nitrate $(34 \% \mathrm{~N})$ at $176.5 \mathrm{lb} / \mathrm{A}(60$ lb N/A). The study was direct sprayed with Cotoran @1 qt/A + Karmex@1.5 lb/A + Induce@ 2 qt/100 gal of solution on 23 June. Cotton was broadcast sprayed with Mepex @12 oz/A + Agridex oil @ 2 pt/A + Kinetic@ 9 oz/100 gal of solution on 30 June, Poast Plus@ 3.75 pt/A + Agridex oil @ 2 pt/A on 9 July, Mepex @12 oz/A + Agridex oil @ 2 pt/A + Kinetic @ 9 oz/100 gal of solution on 17 July, Mepex @16 oz/A + Agridex oil @2 pt/A + Kinetic@ 9 oz/100 gal of solution on 30 July, Penncap M @ 3 pt/A on 31 July, Mepex @8 oz/A + Induce @ 1 qt/A on 20 August, Baythroid 2 @ 2.6 oz/A + Induce @ 1 qt/A on 25 August, and defoliated with Finish @ 1.5 pt/A + Ginstar @ 6 oz/A on 17 October. On 20 and 21 November, the variety trial was picked with the Cotton Spindle Picker. The study was irrigated with 0.5 inch water on 13 and 15 May.

\section{Roundup Ready Variety Trial}

On 8 May, 26 Roundup Ready cotton varieties were planted in this trial and fertilized with 3-9-18 $\left(\mathrm{N}-\mathrm{P}_{2} \mathrm{O}_{5}-\mathrm{K}_{2} \mathrm{O}\right)$ fertilizer at $400 \mathrm{lb} /$ A placed 2-3 inch from the planted row using an FP row fertilizer applicator. Cotton was broadcast sprayed with Roundup WeatherMax @ 1 pt/A on 9 May, and Roundup WeatherMax @ 1 qt/A + Dual 2 Magnum @ $1 \mathrm{pt} / \mathrm{A}$ on 23 May. On 10 June, cotton was side-dressed with ammonium nitrate $(34 \% \mathrm{~N})$ at $176.5 \mathrm{lb} / \mathrm{A}$ (60 lb N/A). The study was direct sprayed with Cotoran@1 qt/A + Karmex@1.5 lb/A + Induce @ $2 \mathrm{qt} / 100$ gal of solution and broadcast sprayed with Mepex @16 oz/A + Agridex oil @ 2 pt/A + Kinetic @ 9 oz/100 gal of solution on 23 June. On 24 June, cotton was broadcast sprayed with Staple @ 1.8 oz/A + Induce @ 1 qt/100 gal of solution. The study was broadcast sprayed with Mepex @ 12 oz/A +Agridex oil @2 pt/A + Kinetic @ 9 oz/100 gal of solution on 17 July, Mepex @ 16 oz/A + Agridex oil @ 2 pt/A + Kinetic @ 9 oz/100 gal of solution on 30 July, Penncap M @ 3 pt/A on 31 July, Mepex @ 8 oz/A + Induce @1 qt/A on 14 August, Baythroid 2 @ 2.6 oz/A + Induce @ 1 qt/A on 25 August, and defoliated with Finish@1.5 pt/A + Ginstar @ 6 oz/A on 7 October. On 21 and 22 November, the variety trial was picked with the Cotton Spindle
Picker. The study was irrigated with 0.3 inch water on 9 May and 0.5 inch water on 13 and 15 May.

\section{Results}

The seed + lint and lint yields, percent lint, and lint quality analysis for the Early and Mid + Full Season, and Roundup Ready cotton are shown in Tables 1-3.

\section{Key Management Considerations for Cotton Production}

1. Variety selection - check variety trials from as many locations close to your area as possible to select those varieties that yield high and have good lint characteristics.

2. Conservation tillage - Strip-till planting decreases erosion, increases soil organic matter, soil moisture, and improves soil texture and may result in increased yields. Cover crops should be killed 3 to 4 weeks prior to planting to reduce insect problems and prevent soil moisture depletion.

3. Planting dates - plantings made from mid April to mid-June are suitable for cotton in Florida.

4. Plant populations - desired cotton plant population is 2-3 plants per foot of row. To get this population, plant 4-5 seeds per foot of row.

5. Adequate and timely $\mathrm{N}$ fertilization - both insufficient and excess nitrogen can lead to fruit shed or boll rot. Nitrogen should be applied near the row, early in the season at first squaring. Two applications may be made on sandy soils (at squaring and 3 weeks later). The recommended rate of nitrogen ranges from 50 to $90 \mathrm{lbs}$ N/A on most soils.

6. Weed control - effective weed control is one of many critical components of successful cotton production. Weeds must be controlled early for best yields and lowest cost. Use of varieties with insect and herbicide tolerance make management decisions easier. 
7. Insect control - effective scouting with timely and proper insect management of bollworms, armyworms, and stinkbugs is very important.

8. Timely defoliation and harvest - if the defoliation is delayed until $60-65$ percent of the total crop to be harvested is open, 90 percent of the crop can likely be harvested within two weeks after the application. 


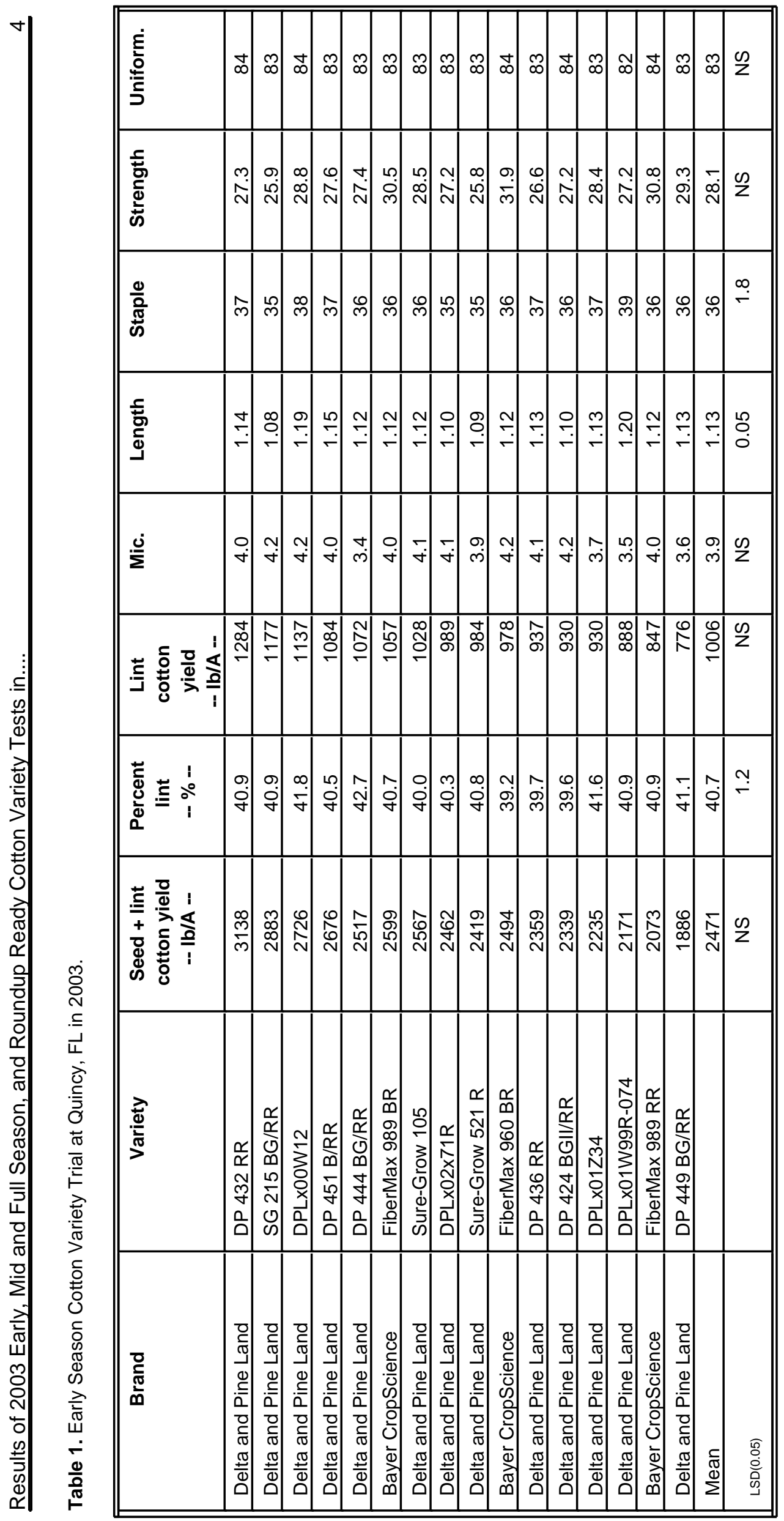




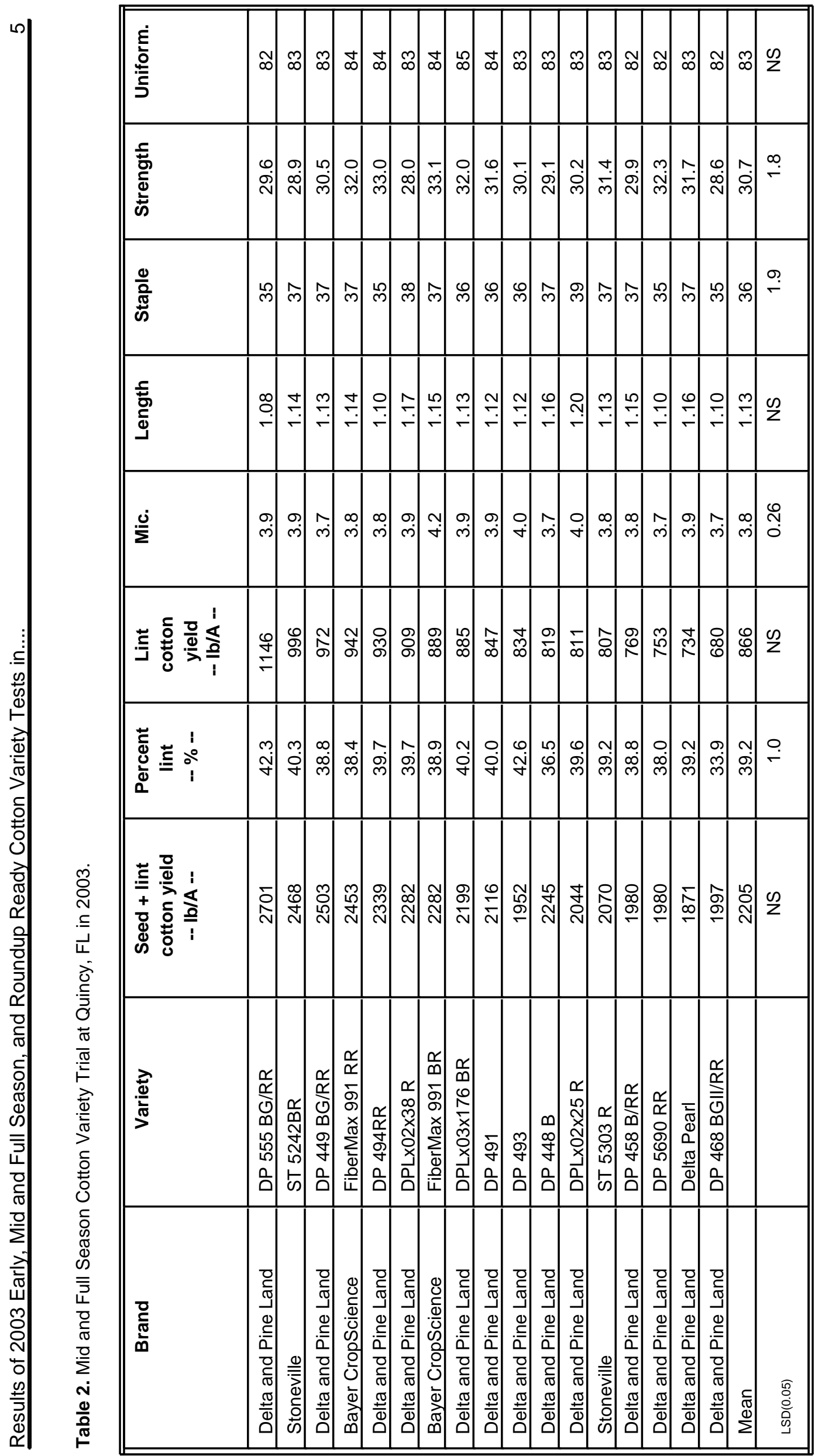




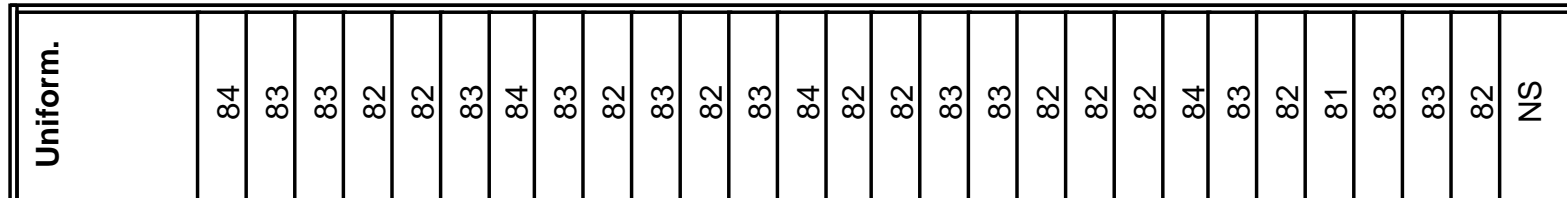

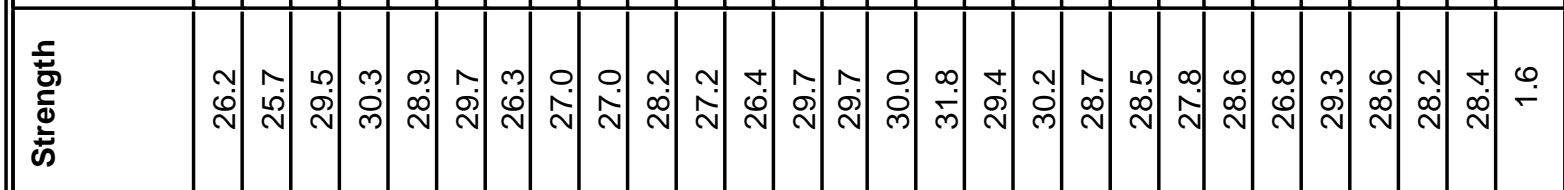

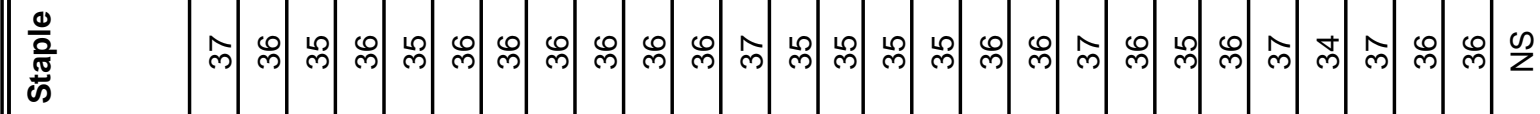

| 焉

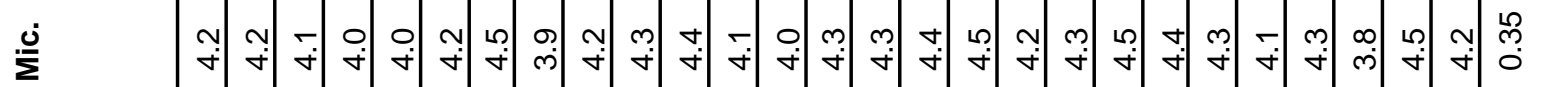

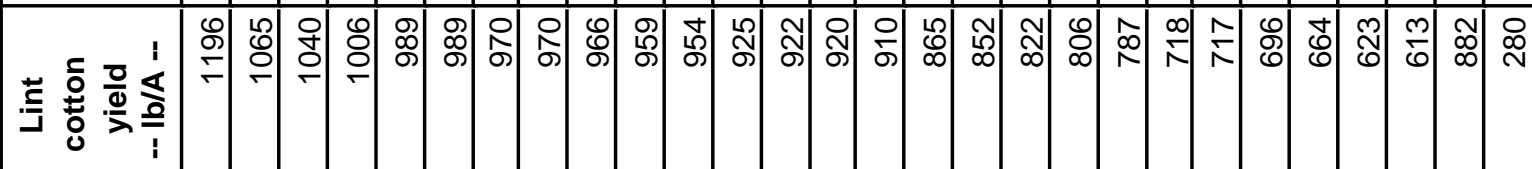

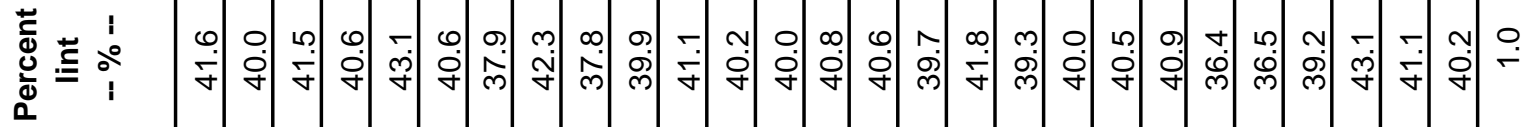

妾 $\frac{0}{0}$

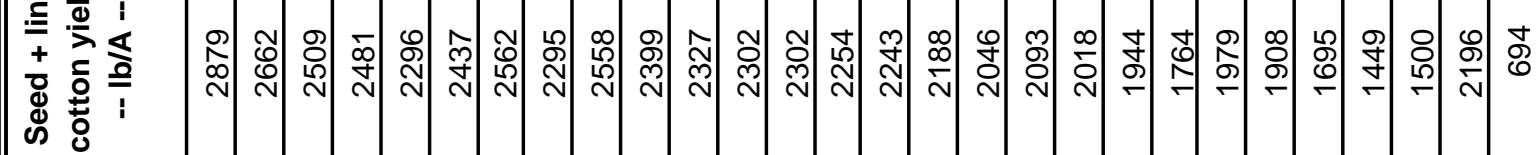

(1)

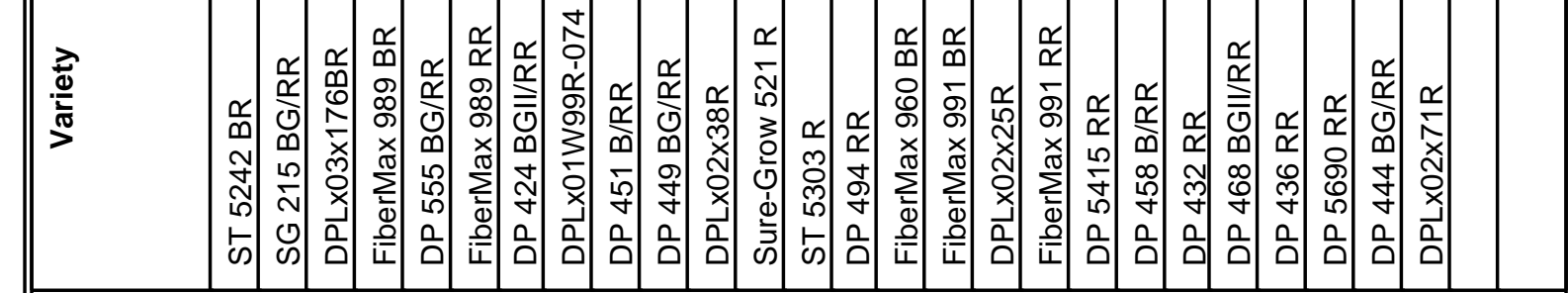

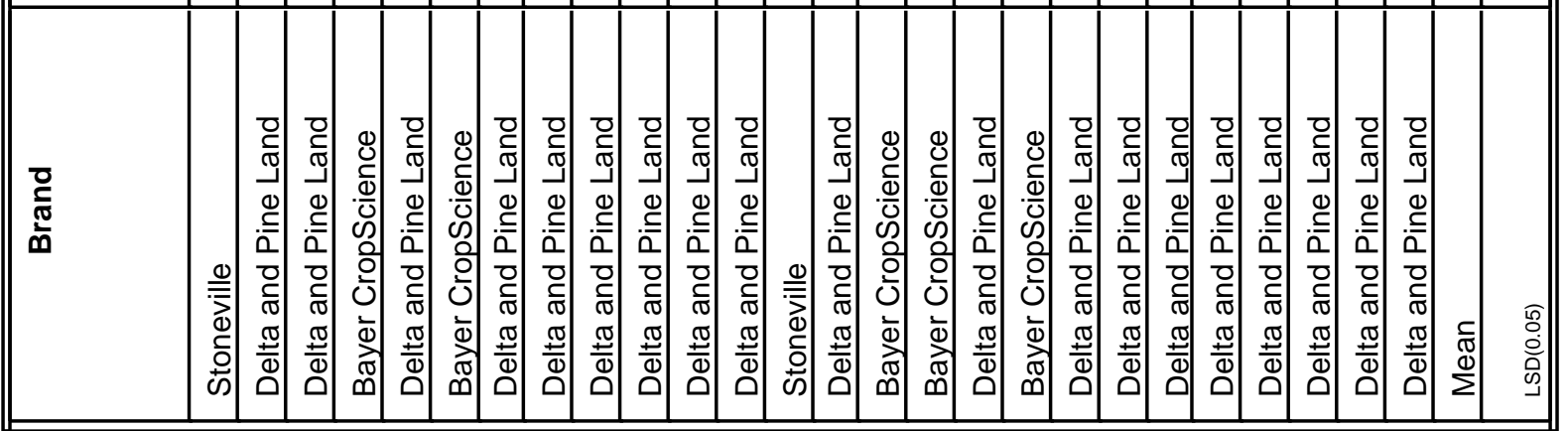

